
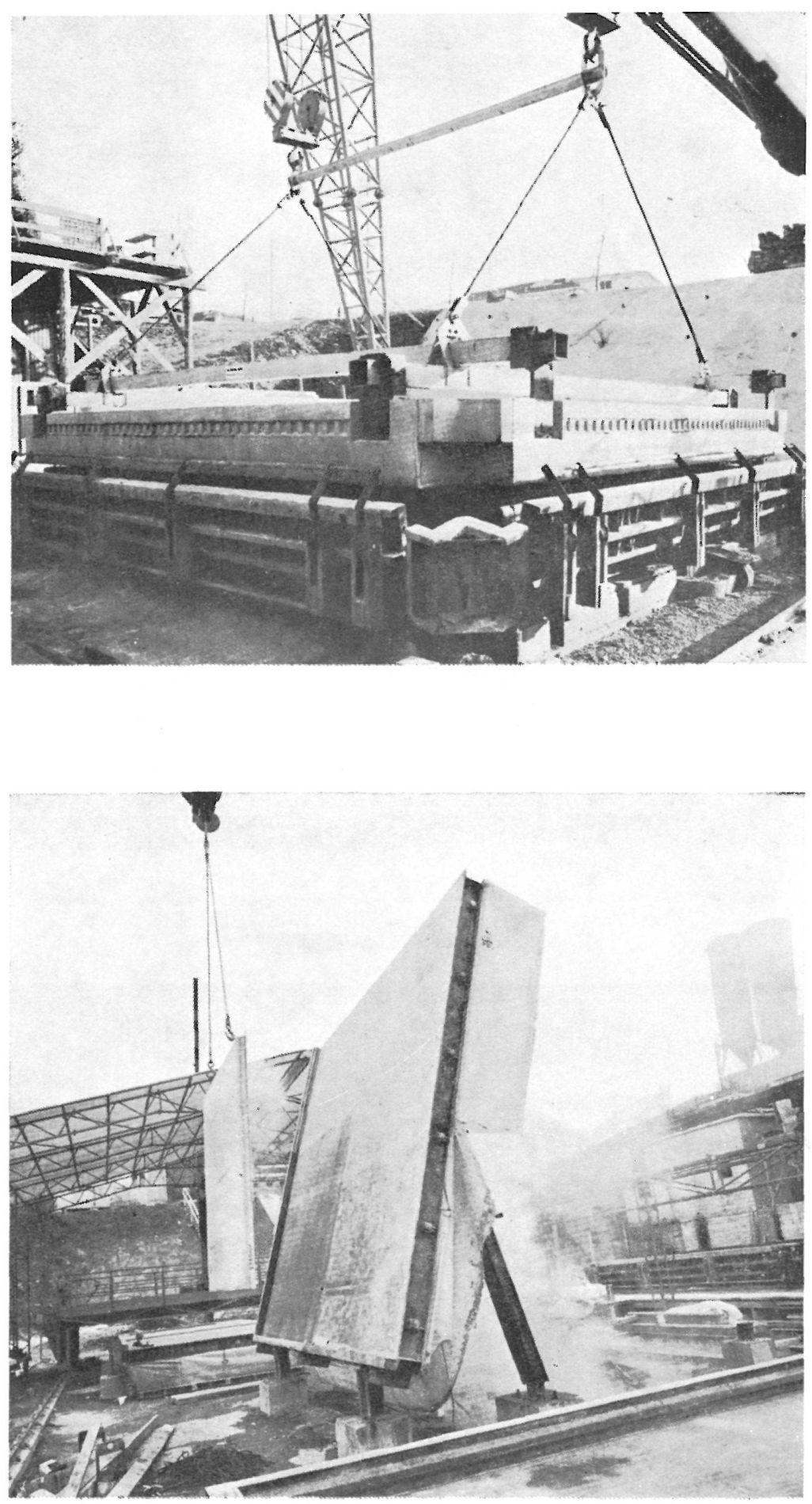

equipos técnicos, con las tuberías, entramados, etc.

La prefabricación pesada es, en definitiva, un medio de realización eficaz, económico y de gran porvenir.

Puede usarse en muchas obras tales como locales industriales, grandes almacenes, aparcamientos, escuelas, hospitales, etc., permitiendo, en numerosos casos, una solución moderna y eficaz con respecto a los criterios de:

\section{a) Calidad}

- Un acabado de gran precisión, pudiéndose prescindir de paneles.

- Un interesante aspecto de la superficie, limpio de desencofrado.

- Un buen comportamiento de cara a las vibraciones.

- Utilización de los materiales para el máximo de presiones admisibles.

\section{b) Coste}

- Utilización de una metodología de vanguardia.

- Empleo de una proporción de mano de obra pequeña (menos del $50 \%$ de una obra normal).

- Una menor sensibilidad a las subidas de precios (en particular las debidas a la mano de obra).

- Reducción de las subidas alrededor de un $50 \%$.
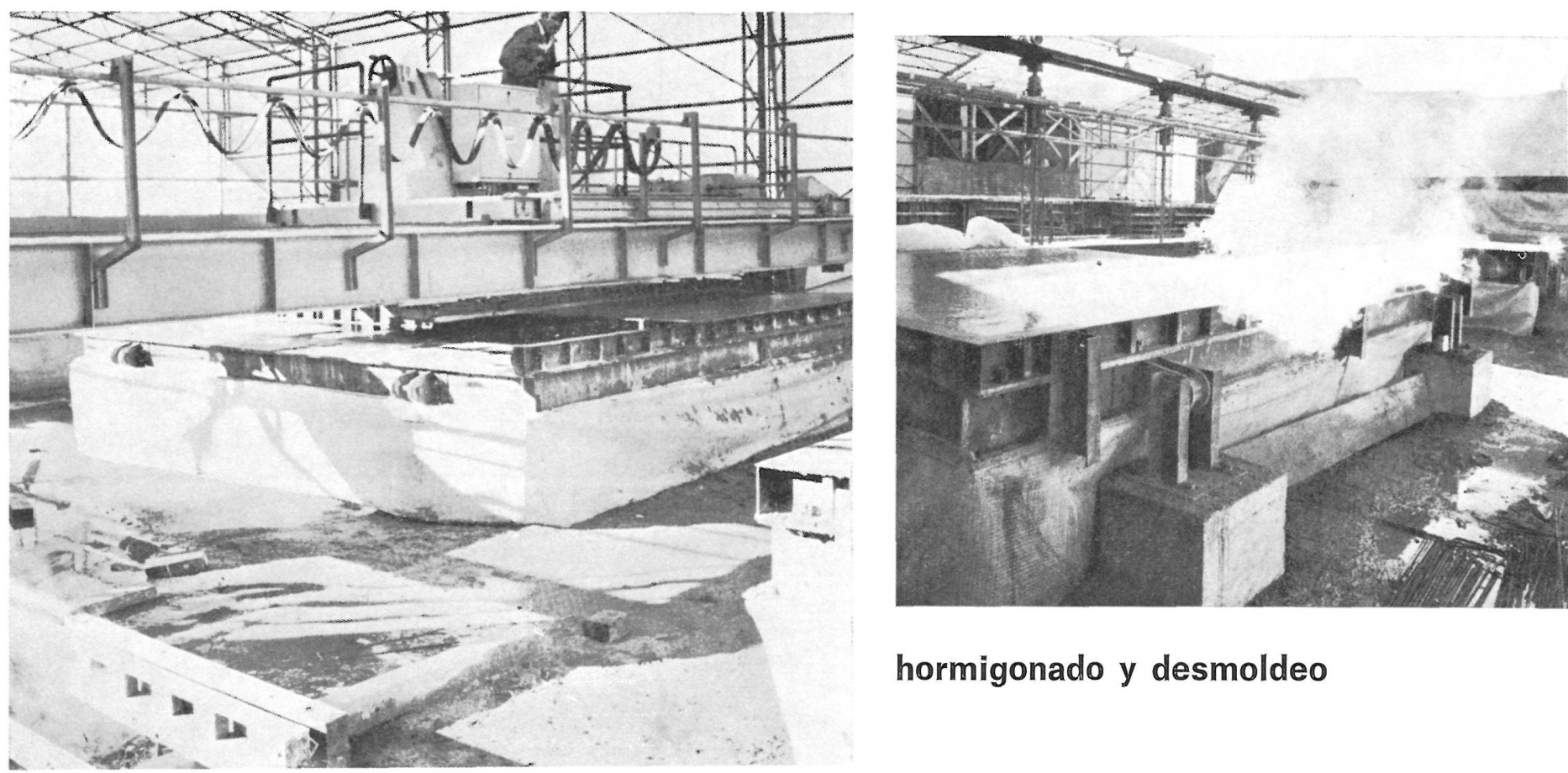

hormigonado y desmoldeo 


\section{almacenamiento y transporte}

\section{c) Plazos}

- Ritmo de colocación y fabricación muy rápida.

- Poca sensibilidad a las condiciones atmosféricas.

Un ejemplo de realización con prefabricación pesada es el centro industrial y artesano de Sevelin, construido por cuenta de MOBAG, en un terreno cedido por la ciudad de Lausana.

Esta obra, con una superficie de $78.000 \mathrm{~m}^{2}$ y un volumen de $290.000 \mathrm{~m}^{3}$, se ha realizado totalmente en el corto plazo de 27 meses.

Se utilizaron placas prefabricadas de un peso de 36 a 38 t destinadas a muros interiores, muros-filtros, zanjas y núcleos de arriostramiento.
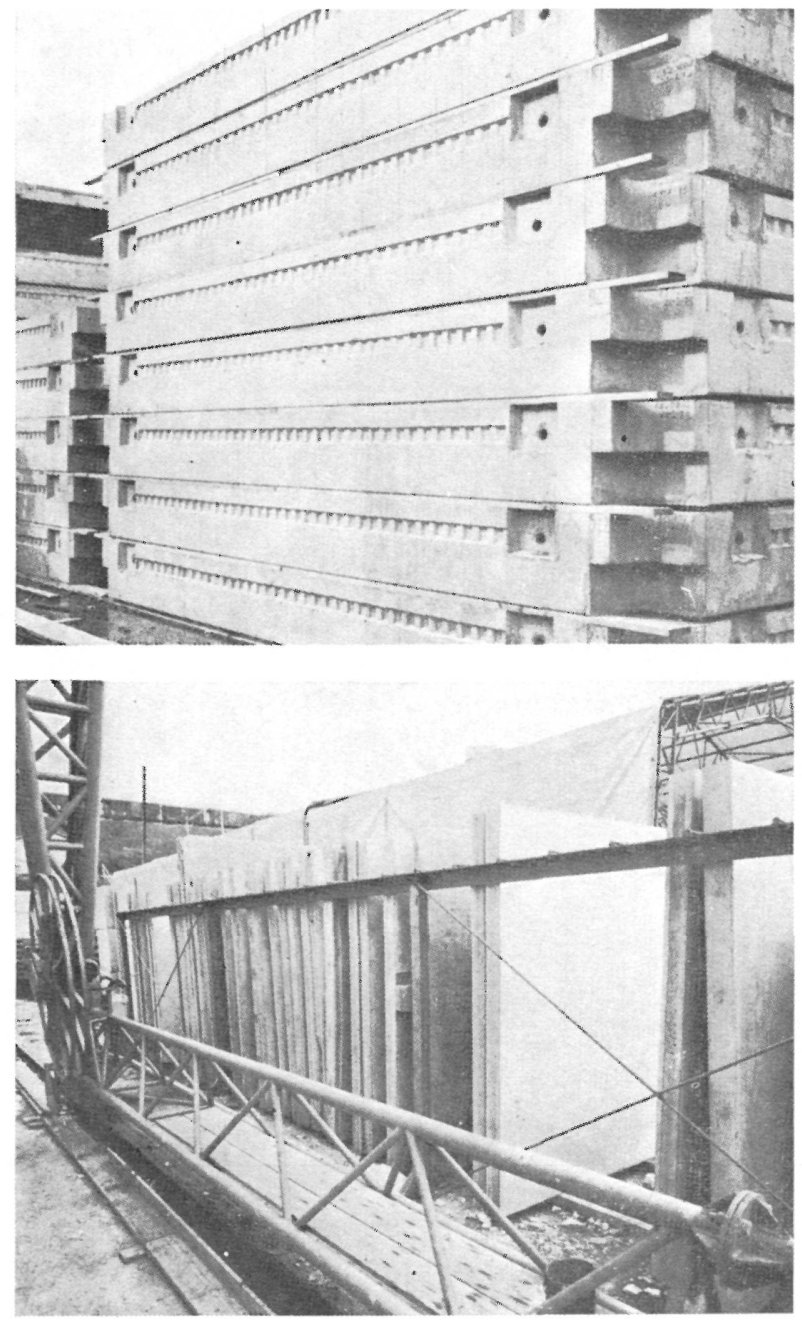

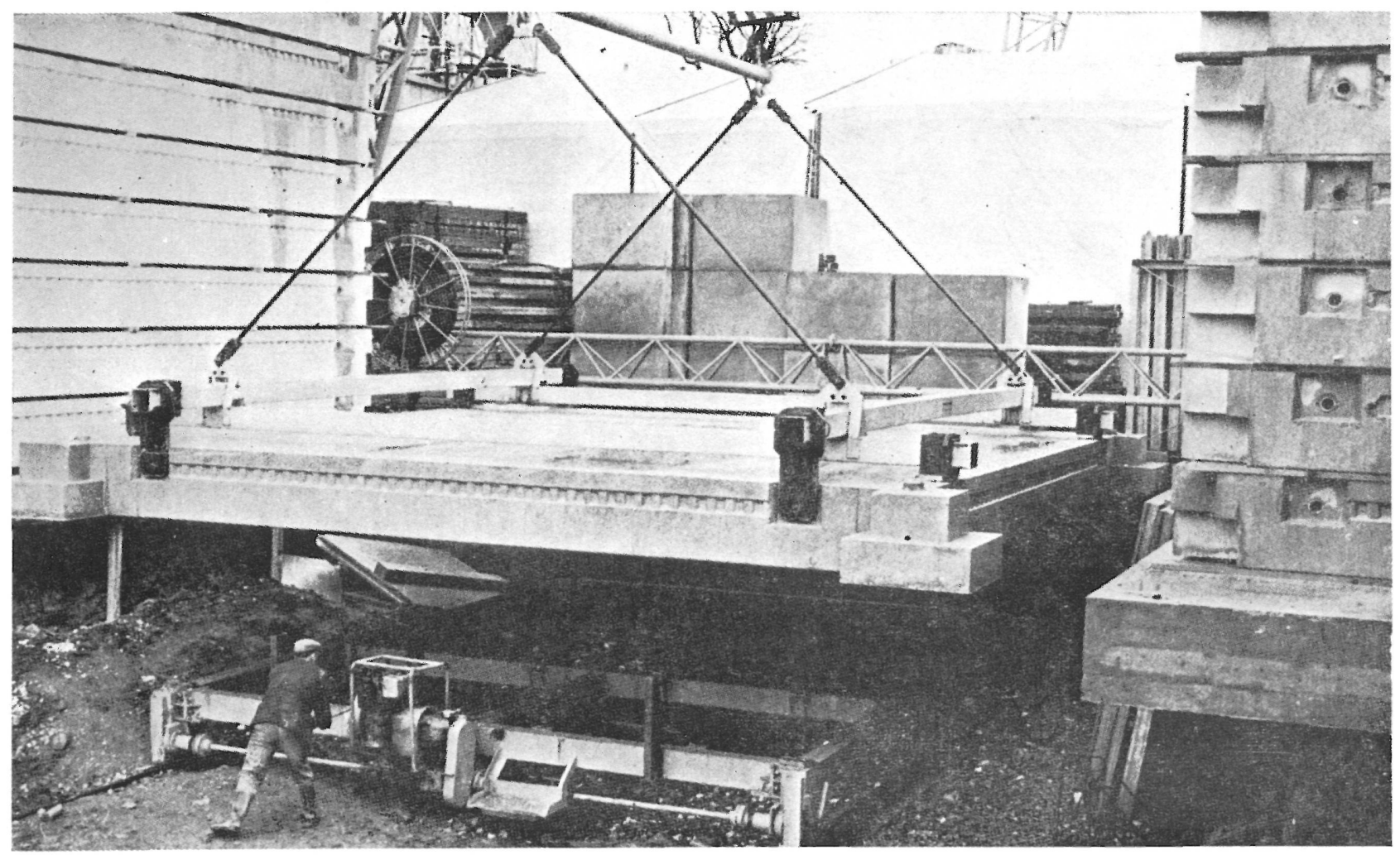

estucado y transporte 


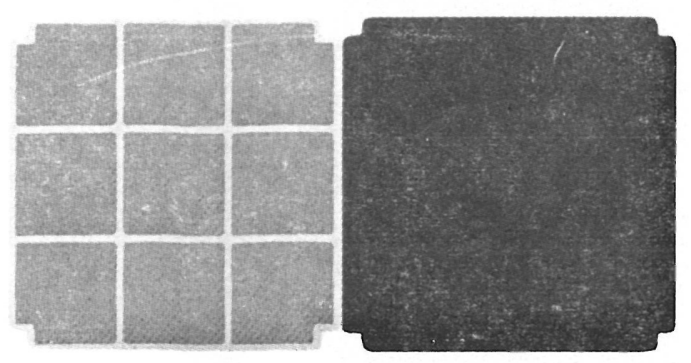

unión de losas
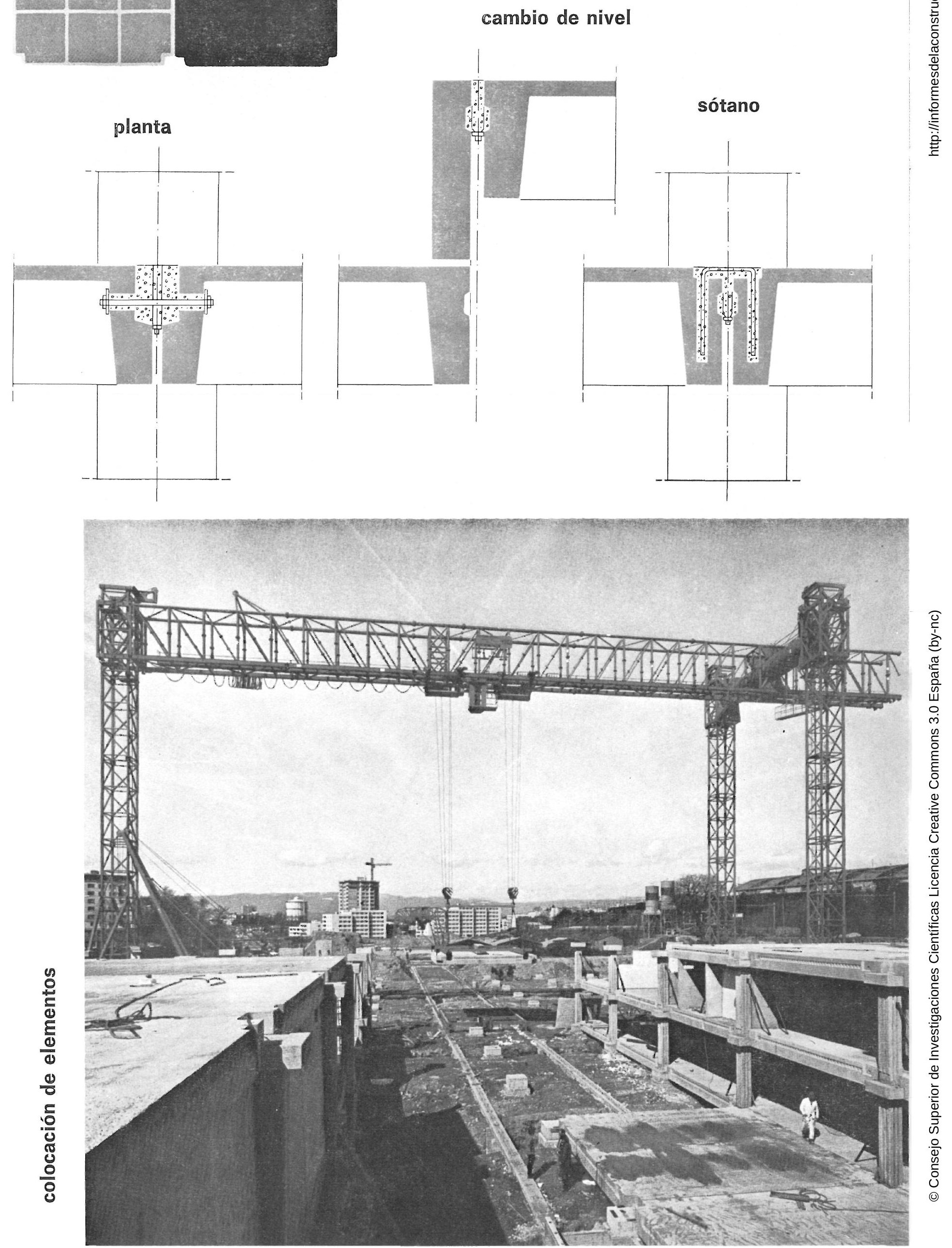

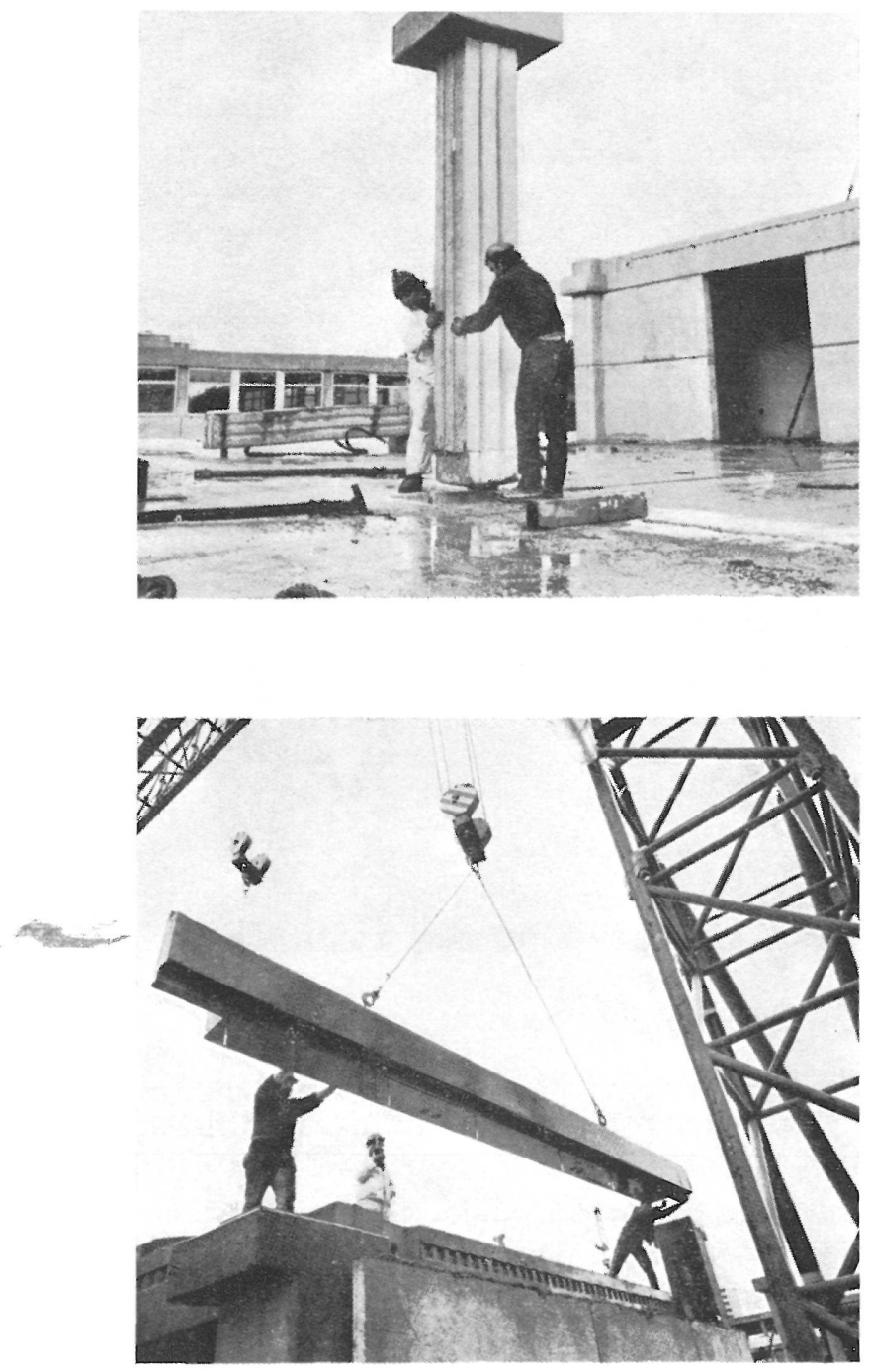

\section{colocación de elementos}

El proceso a seguir fue:

a) Colocación de las armaduras:

- preparación del entramado de las armaduras en los encofrados de hormigón;

- manipulación de las armaduras con un pequeño pórtico-grúa.

b) Preparación de las placas:

- colocación de las armaduras en el encofrado;

- colocación de los tubos y cajas de derivación eléctricas.

c) Fabricación del hormigón en una estación de amasado y transporte, totalmente automática, con una capacidad de fabrica. ción de $20 \mathrm{~m}^{3} /$ hora.

d) Hormigonado de las placas mediante un tren de hormigonado que comprende:

- una distribuidora,

- una compactadora,

- una reguladora, y

- una alisadora,
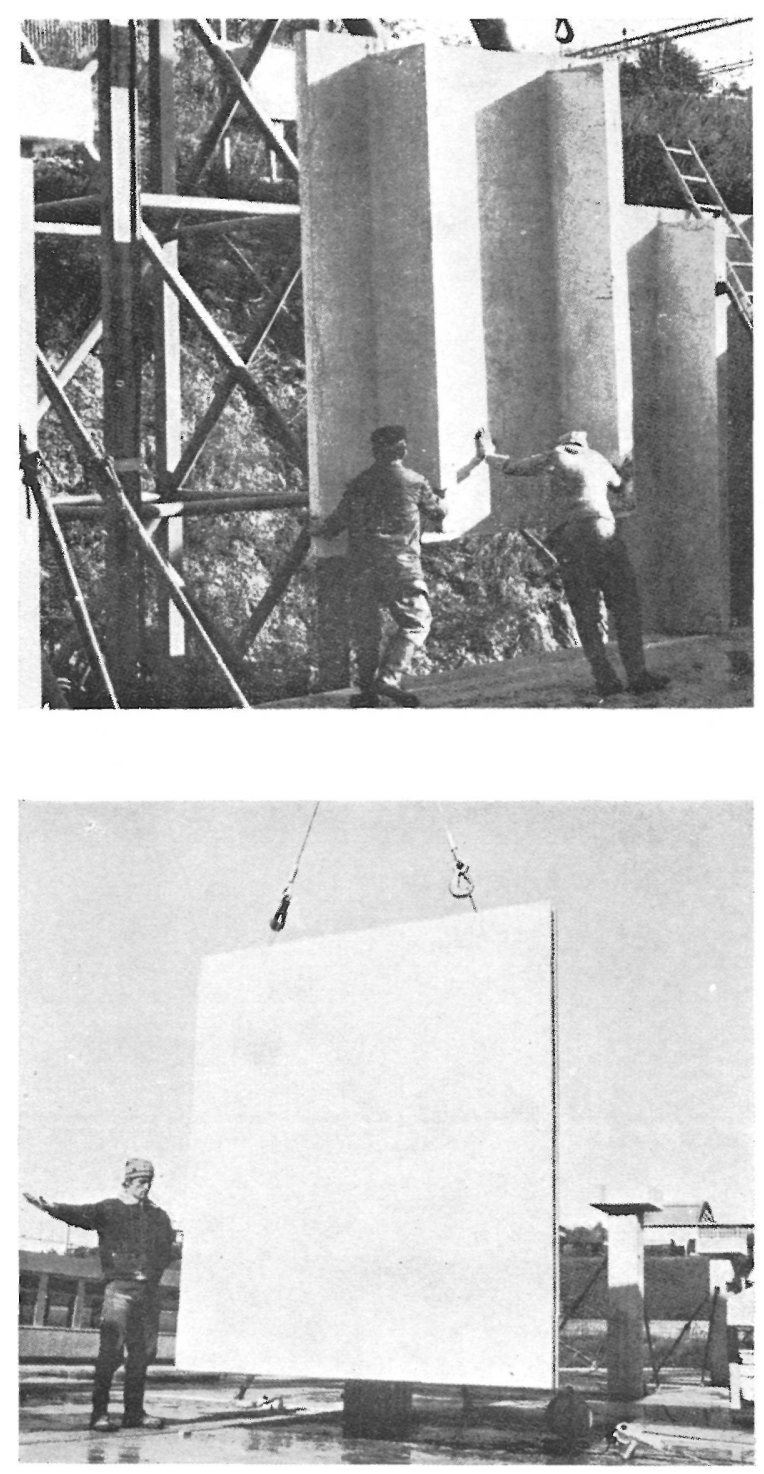

con una producción de hasta cinco placas por día $\left(320 \mathrm{~m}^{2}\right)$-dimensiones $8 \times 8 \mathrm{~m}$ - Después se llevó a cabo un curado al vapor para desencofrarlo a partir de las 15 horas.

e) Hormigonado de los muros utilizando el mismo tren de hormigonado de las placas. También se utiliza un curado al vapor de los muros.

f) Una vez desencofrados los muros y placas son almacenados para su posterior transporte.

g) Transporte de dichos elementos mediante vagón.

El montaje de estos elementos se realizó en las siguientes fases:

1) Colocación de los elementos de apoyo como pilares - de 4 a 6 t de peso-y durmientes - de 6 a $9 \mathrm{t}$ de peso-.

2) Colocación de los muros exteriores - de un peso de 2,5 t-y de los muros interiores (traviesas).

3) Colocación de las placas, a un ritmo de hasta 20 placas - de un peso de 36 a $38 \mathrm{t}$ - por día, o sea, $1.280 \mathrm{~m}^{2}$.

4) Acabado de la construcción. 
